\author{
Cadernos de \\ ESTUDOS LINGǘlSTICOS - (54.1), Campinas, Jan./Jun. 2012
}

\title{
REPETIÇÕES HESITATIVAS EM FALA AFÁSICA E NÃO-AFÁSICA ${ }^{1}$
}

\author{
JANAISA MARTINS VISCARDI ${ }^{2}$
}

\begin{abstract}
RESUMO
O texto discute as repetições hesitativas produzidas em fala afásica e não-afásica em frases nominais e preposicionais, a partir de suas características prosódicas e dos movimentos de retração e projeção, como discutidos em Auer (2009a). Entre as semelhanças entre a fala afásica e não-afásica destacam-se 1) o alongamento vocálico associado ao movimento de curva entoacional descendente na caracterização da repetição hesitativa, 2) a presença dos mesmos movimentos de retração simples e múltipla em ambos os grupos e 3) uma maior similaridade das características prosódicas dos dois grupos nos casos de retração múltipla. Entre as diferenças mais importantes, destacam-se 1) a distribuição da ocorrência das retrações simples e múltiplas - afásicos produzem um número significativamente maior de retrações múltiplas - e 2) a extensão das características hesitativas ao longo de toda a estrutura de repetição na fala afásica, enquanto na fala não-afásica essas características se encerram na penúltima repetição. Este estudo procura oferecer uma melhor compreensão do emprego dos recursos prosódicos pelos sujeitos afásicos e não-afásicos em contextos interativos e, através disso, permite identificar a maior ou menor relevância de determinados recursos linguísticos em ambientes específicos de produção, como no caso das repetições hesitativas.
\end{abstract}

Palavras-chave: repetição, prosódia, afasia.

\begin{abstract}
This article analyzes the prosodic parameters which underlie the activity of hesitational repetitions in the production of nominal and prepositional phrases by aphasic and nonaphasic speakers. The most relevant aspects of the analysis are 1) the relationship between the movements of retraction and projection, as described in Auer (2009a), during the production of the hesitational repetitions, 2) the relationship between the prosodic parameters, namely, the fundamental frequency and the duration, and finally, 3) the co-occurrence between the prosodic parameters and the movements of retraction and projection during the production of hesitational repetitions. Among the similarities between the two groups analyzed are a) the vowel lengthening associated with the downward intonation curve in the characterization of the hesitational repetitions, 2) the occurrence of the same retraction movements in both aphasics and nonaphasics and 3) a greater similarity of prosodic features in the two groups in cases of multiple retraction. Among the most important differences are 1) the distribution of single and multiple retractions - aphasics produce a significantly greater number of multiple retractions - and 2)
\end{abstract}

1. Este artigo foi desenvolvido a partir da Tese de Doutorado da autora, orientada pela profa. Edwiges Morato e apresentada à Universidade Estadual de Campinas. A pesquisa contou com o apoio financeiro da CAPES (Coordenação de Aperfeiçoamento de Pessoal de Nível Superior), no Brasil, e do DAAD (Deutscher Akademischer Austausch Dienst), na Alemanha.

2. Doutora em Linguística pela UNICAMP, Professora Assistente das Faculdades Tecnológicas SENAI. e-mail: isaviscardi@yahoo.com.br; janaisa@gmail.com. 
VISCARDI - Repetições hesitativas em fala...

the extent of the features of hesitation throughout the structure M R1 Rx in aphasic speech. This study promotes a better understanding of the use of prosodic features by aphasic and nonaphasic speakers and assigns the relevance of certain linguistic resources in specific production environments, as in the case of hesitational repetitions.

Keywords: repetition, prosody, aphasia.

\section{INTRODUÇÃO}

$\mathrm{Na}$ fala espontânea os sujeitos organizam, a todo momento, recursos linguísticos, cognitivos e interacionais que são empregados durante o processo de construção do sentido no decorrer da atividade verbal. Essa qualidade da fala espontânea permite estudar os diferentes conhecimentos que são articulados durante o processo de produção e compreensão da linguagem. Por sua riqueza, permite entrever não só o andamento da conversa, mas como esse andamento se desenrola, com as mudanças de estilo, com as correções, as reformulações e as contínuas transformações que fazem da linguagem um recurso tão dinâmico.

À Linguística voltada à análise da linguagem em uso interessa, entre outros tópicos, como a fala se modula nos mais variados contextos, como o sujeito se adapta a esses variados contextos e como eles podem influenciar na compreensão. Ao se considerar, por exemplo, a definição de Koch (1997), para quem a produção textual é uma atividade verbal e interacional, criativa e consciente, "que compreende o desenvolvimento de estratégias concretas de ação e a escolha de meios adequados à realização dos objetivos", compreender o emprego das mais variadas estratégias dos falantes é parte fundamental do entendimento da organização e processamento da atividade verbal.

Seguindo este viés, o presente artigo analisa casos de repetição conhecidos como repetições hesitativas em frases nominais e preposicionais (doravante NP e PP, respectivamente), na fala de sujeitos afásicos e não afásicos, ancorado em perspectivas teóricas voltadas justamente à reflexão da linguagem em uso como em Marcuschi (1996, 1999, 2006), Tannen (2007) e Koch (1997). As chamadas "descontinuidades" são vistas, assim, como um traço característico da oralidade (Jubran, 2006) e devem, portanto, ser levadas em conta em uma descrição linguística da produção.

$\mathrm{Na}$ literatura afasiológica, as repetições e hesitações são frequentemente entendidas como indicadores do déficit afásico, assim como as pausas e os alongamentos. Estes elementos são, nos estudos de Afasiologia, usados como parâmetros de avaliação da fluência na fala dos sujeitos afásicos, sendo a capacidade de repetição de palavras produzidas por um interlocutor, por exemplo, um dos pontos aplicados nos testes de avaliação da fala afásica (veja, por exemplo, Rohrer et al, 2008; Moses, Sheard \& Nickels, 2007; Dell, Martin \& Schwartz, 2007; Miceli, Capasso \& Caramazza, 2004; Arbuthnott, 1996; Goodglass \& Caplan, 1972).

Mas, enquanto as definições e terminologias sobre as afasias sugerem a incapacidade, a incompetência linguística dos indivíduos diante de sua nova condição, a observação das condições reais de produção e compreensão linguística 98 
desses sujeitos sugere que a competência para falar e usar a linguagem não é mera capacidade mental, idealizada, mas se constrói através de práticas interativas, sociocognitivas (Morato et al, 2008).

Scarpa $(1995,2006)$ revela o quão idealizada é a visão dos mais variados autores no que tange à definição de fluência, aspecto fundamental inclusive para a determinação daquilo que é entendido como descontinuidade, disfluência, como no caso das repetições aqui analisadas. Scarpa (1995) revela a dificuldade em lidar com a definição de fluência, dado que é fugidia e, inúmeras vezes, tratada pela negativa, ou seja, através de afirmar aquilo que a fala fluente não é: não apresenta pausas, não apresenta repetições, não apresenta alongamentos, como a própria definição de Fillmore (1979) sugere. Ainda que o emprego do termo fluência possa parecer claro a médicos e fonoaudiólogos, os parâmetros que levam os falantes a perceber determinada fala como fluente não são tão claros quanto se sugere.

Este artigo, ao analisar casos de repetição hesitativa em fala afásica e não-afásica, busca justamente compreender o funcionamento dessas chamadas "imperfeições" da produção, na busca por uma melhor descrição e compreensão da fala, seja ela afásica ou não-afásica.

\section{AS REPETIÇÕES HESITATIVAS: DOIS FENÔMENOS EM UM}

Este estudo parte do pressuposto de que a repetição e a hesitação são fenômenos recorrentes na fala cotidiana. Koch (1997: 91) afirma que a hesitação é “(...) constitutiva do próprio processo de construção do texto falado, ligada à possibilidade mesma de sua emissão, já que nele, como já mostramos, planejamento e verbalização são necessariamente simultâneos, pondo-se a nu, a cada momento, o processo de sua construção".

Já a repetição é tida como atividade de formulação, “uma estratégia básica de estruturação do discurso" (Koch, 1997: 123), mais especificamente, um processo de reformulação, já que sempre se reporta a algo já dito anteriormente. Para Marcuschi (2006), longe de ser apenas uma característica superficial da inconstância da oralidade, a repetição revela dinamicidade na organização da atividade verbal e na monitoração da coerência textual, realizando um variado conjunto de funções.

De acordo com Marcuschi (2006), as repetições se dividem entre auto e hetero-repetições, podem ocorrer tanto no mesmo turno quanto em turnos distintos e ser composta por distintos segmentos, ou seja, fonemas, morfemas, itens lexicais, construções suboracionais ou orações. Neste artigo, importam-nos os casos de auto-repetição, que equivalem a $80 \%$ das ocorrências de repetições, de acordo com Marcuschi (2006).

E como a hesitação se conecta à repetição? Aquilo que é chamado de hesitação define-se, em inúmeros casos, a partir de correlatos fonético-fonológicos, ou seja, através das pausas e dos alongamentos. As pausas, os alongamentos e as possíveis alterações de fonação que acompanham as repetições motivam não só as mudanças estruturais em si mesmas, como também das funções que carregam as repetições 
VISCARDI - Repetições hesitativas em fala...

e das pistas de contextualização (Gumperz, 1982) que podem ser encontradas em diferentes sequências de fala.

Esses elementos, combinados à repetição de um artigo ou de uma preposição, por exemplo, compreendem ação antecipatória, corretiva e organizadora da fala. Esse caráter antecipatório atribuído à hesitação constitui, junto da repetição, uma projeção em diferentes níveis: no nível interacional e fonético-fonológico, pela hesitação, e no nível sintático, pela repetição.

Assim como em fala não-afásica, no contexto das afasias a repetição e a hesitação são também fenômenos recorrentes que atuam na delimitação de segmentos tópicos e nas atividades de estruturação textual e interacional do tópico conversacional, como indica o estudo de Tagliaferre (2008), bem como na dinâmica e no monitoramento de tomadas e trocas de turno, como assinala Mira (2012).

Para poder descrever a dinamicidade do emprego de NPs e PPs e perscrutar seu papel nos fragmentos de conversação em análise neste texto, somente uma perspectiva que preveja essa dinâmica poderia ser considerada. Além disso, as repetições implicam uma retomada de um item já ativado anteriormente, o que levou à consideração dos trabalhos de Auer (2009a, 2009b) e Auer \& Pfänder (2008) na caracterização de suas ocorrências, assim como na determinação das categorias de análise.

Auer (2009a), em seu texto que trata das operações sintáticas envolvidas no processamento online da fala, sistematiza o conjunto de operações envolvidas em três elementos, dos quais dois nos interessam aqui: a projeção e a retração.

Por retração, entende-se o mecanismo que "se refere retroativamente a estruturas sintáticas já existentes, e que são reativadas e modificadas"3 (Auer, 2009a:4). A retração opera tanto retroativamente quanto prospectivamente: ao mesmo tempo que uma estrutura sintática é repetida no plano sintagmático, ela é renovada no plano paradigmático, dada a possibilidade simultânea de reutilização da estrutura sintática e acréscimo de novo vocabulário ou mudança fonéticofonológica.

Já a projeção é uma operação que implica a possibilidade de predicabilidade: quando uma estrutura sintática começa a ser produzida, o ouvinte cria uma expectativa sobre a continuidade daquela estrutura sintática, ou seja, essa dada estrutura projeta um conjunto de possibilidades de continuidade sintática. Quando a estrutura prevista é produzida, a projeção é preenchida. Quanto mais o falante avança na construção de um período, maior a predicabilidade da estrutura seguinte.

\section{METODOLOGIA}

Os aspectos metodológicos concernentes a este trabalho não podem ser expostos sem antes ter vez uma breve apresentação do espaço que motiva o change."

3. (...) refer back in time to already existing syntactic structures which they reactivate and 
desenvolvimento deste trabalho: o Centro de Convivência de Afásicos (doravante CCA).

\subsection{O CCA}

Os dados aqui analisados foram extraídos de episódios de interação no CCA, ocorridos durante o Programa de Linguagem. O Centro, situado nas dependências do Instituto de Estudos da Linguagem (IEL), na UNICAMP, funciona no Laboratório de Neurolinguística (doravante LABONE) desde 1998. O CCA deve ser entendido como uma comunidade de práticas (Morato et al., 2007; Mira, 2007) que reúne sujeitos afásicos e não-afásicos, dentre eles, pesquisadores linguistas, fonoaudiólogos, fisioterapeutas, médicos e também alunos de graduação e pósgraduação das áreas mencionadas, todos engajados na negociação e construção do sentido, por processos verbais e/ou não verbais.

Uma das principais características que define os participantes do grupo é a sua heterogeneidade, visto que pertencem a classes sociais distintas, possuem diferentes graus de escolaridade, enquadram-se em faixas etárias variadas e têm quadros afásicos também variados. É esse conjunto de elementos que permeiam (e permitem) a dinâmica de práticas interativas e interlocutivas no grupo, incluindo aqui uma certa dessimetria interlocutiva (Morato et al., 2007), decorrente justamente das diferenças entre os frequentadores do CCA.

\subsection{O corpus}

Os fragmentos discutidos neste artigo foram extraídos do corpus de investigação de minha Tese de Doutoramento, composto de um conjunto de 12 encontros (equivalentes a cerca de 36 horas de gravação) selecionados do Aphasiacervus, um acervo de dados linguístico-interacionais registrados audiovisualmente dos encontros semanais do CCA. Neste artigo, serão discutidos fragmentos que representam as principais características dos dados daquele corpus para o fenômeno estudado, ou seja, as repetições hesitativas.

\subsection{Critério de seleção dos sujeitos}

Entre os sujeitos afásicos, estão SI e JM, que apresentam quadro de afasia semântica, e NS, que apresenta um quadro de afasia transcortical. JM e SI têm diagnósticos semelhantes no que tange ao tipo de afasia; apresentam, no entanto, características e posturas bastante distintas frente às interações com o grupo. Tímida e reservada, SI fala pouco. Já JM e NS são bastante comunicativos. Os três sujeitos apresentam dificuldades de encontrar palavras, realizando com frequência os casos de repetição hesitativa aqui analisadas.

A escolha dos sujeitos afásicos levou em conta não somente uma certa simetria nas características de seus quadros afásicos, mas também as características de sua produção em contexto de interação social e a participação no conjunto de atividades desenvolvidas nos encontros. 
VISCARDI - Repetições hesitativas em fala...

Os sujeitos não afásicos são EM, HM e FC. Os três são participantes bastante conhecidos do grupo e participam ativamente das atividades promovidas pelo CCA.

\subsection{A transcrição dos dados para análise}

As transcrições dos fragmentos apresentados neste artigo seguem a notação sugerida por Selting et al (1998). Dois programas foram utilizados para facilitar o trabalho de transcrição: o Praat ${ }^{4}$ e o Transformer ${ }^{5}$. Com a ajuda do Praat, foi possível refinar a transcrição, mantendo a norma ortográfica do Português, e marcar duração, pausa e pitch. No Transformer, as transcrições feitas no Praat foram transformadas em arquivos de texto e formatadas automaticamente de acordo com a notação de transcrição de Selting et al (1998) .

\section{PARÂMETROS DE ANÁLISE}

Neste trabalho, está em foco a repetição que remete a uma unidade sintática (uma frase nominal ou preposicional) já iniciada e, na sequência, retomada na fala do sujeito. São três os aspectos observados no interior das ocorrências das repetições hesitativas em NPs e PPs: I. a relação entre os elementos sintáticos constituintes da oração, em termos de projeção e retração (Auer, 2009a); II. a relação entre os elementos prosódicos da oração, a saber, a duração (dos segmentos e de pausas que os antecedem e sucedem) e o pitch; e III. a relação entre os elementos I e II, entendidos como pistas de contextualização que marcam a produção.

\section{EXEMPLOS DE REPETIÇÕES HESITATIVAS \\ 4.1. Repetições simples em sujeitos afásicos e não afásicos}

No primeiro fragmento do qual nos ocuparemos, participam da conversa MS e NS (afásicos) e EM (não-afásica). Os três participantes discutem o processo eleitoral para presidência do País em curso naquele momento. NS acaba de defender seu ponto de vista, explicitando porque votará em um dos candidatos à presidência, a saber, Lula. EM sugere, então, que os participantes do sexo masculino apresentem seus argumentos para justificar o voto em outro candidato à presidência, Geraldo Alckmin. $\mathrm{O}$ recorte apresentado abaixo foi feito a partir desse ponto da interação. Será na retomada do turno de fala (que vinha sendo desenvolvido por NS e também HM, não-afásica) que EM produzirá o primeiro caso em análise aqui.

\footnotetext{
${ }^{4}$. Desenvolvido por Paul Boersma e disponível gratuitamente no endereço http://www.praat.org

5. Desenvolvido por Oliver Ehmer e disponível gratuitamente no endereço http://www. oliverehmer.de/transformer/

6. A notação está parcialmente transcrita no final do artigo. Para informações detalhadas sobre a notação, vide Selting et al (1998)
} 


\section{Trecho [1] AphasiAcervus 19.10.06}

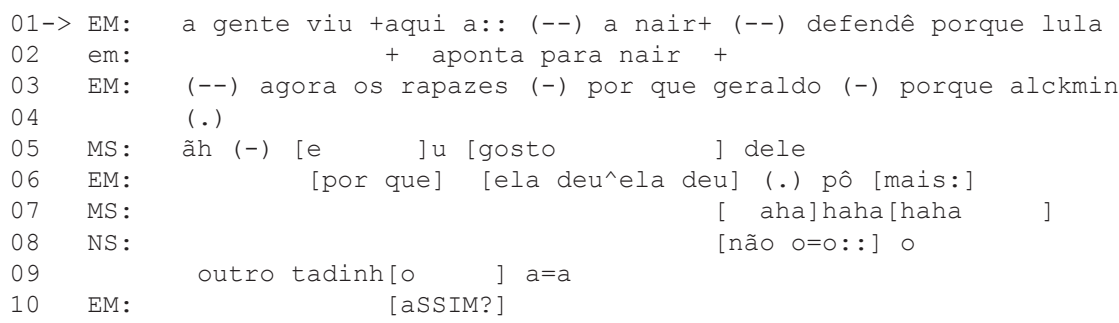

Quando EM pergunta a MS e JM por que votarão em Geraldo Alckmin, candidato opositor a Lula, MS responde que gosta dele. Surpresa com essa justificativa, EM questionará MS, através da reformulação do que inicialmente vinha dizendo, na linha 06.

Em primeiro lugar, é preciso destacar o papel do conhecimento partilhado entre os sujeitos que frequentam o CCA sobre suas opiniões e, mais especificamente neste caso, sobre suas orientações políticas. Os rapazes aos quais EM se refere, na linha 03, são dois participantes do grupo (MS e JM, afásicos) que têm declarada sua orientação política, a saber, sua preferência pelo voto em Geraldo Alckmin, enquanto NS acaba de declarar, e justificar, seu voto em Lula.

Ao propor que os participantes JM e MS justifiquem sua preferência (linha 01 a 03 ) - ponto em que o fragmento 1 é iniciado -, EM realiza o primeiro padrão de repetição no qual nos deteremos aqui: a produção do artigo $a$, alongado, e sua repetição, depois de uma pausa, seguida do nome que completa o NP. O processo de realização do NP consiste, neste primeiro caso, de três momentos: a produção inicial do artigo, uma pausa, e a retomada da fala, com a produção do artigo seguida do nome.

$$
\begin{array}{r}
\text { a gente viu aqui a:: } \\
\text { a nair }
\end{array}
$$

A repetição, que pode exercer diferentes funções, retoma aqui a estrutura NP inicialmente projetada pela produção do determinante. A matriz $a$ projeta um NP e as características prosódicas de sua ocorrência sugerem o momento de hesitação na fala.

Dentre as características prosódicas destacam-se a duração duas vezes maior do artigo $a$ em relação à sua repetição e a curva entoacional descendente na produção da matriz. 


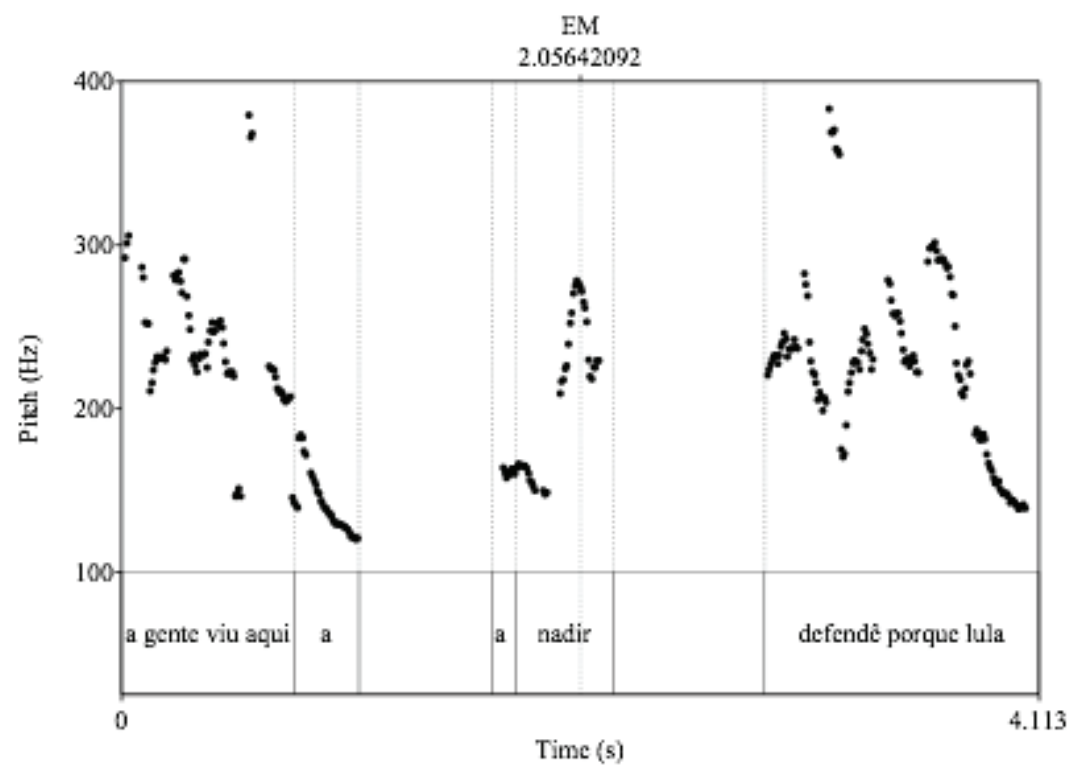

Figura 1. Curva entoacional para "a gente viu aqui a::: a nair."

Este primeiro exemplo ilustra bem um dos padrões possíveis em repetições simples na fala de sujeitos não-afásicos: na produção do complemento de um verbo, o artigo que introduz o NP é alongado. Durante sua produção, há queda progressiva da curva entoacional, atingindo um nível bastante baixo quando comparado ao que vinha sendo produzido ao longo da frase entoacional. A repetição do artigo determina a retomada da fala, que acontece já em um nível entoacional mais elevado em relação ao nível que finalizou a produção do artigo anterior.

Observemos, em contrapartida, como se desenrola um exemplo de retração simples em sujeitos afásicos. NS (afásica) está relatando o que viu na televisão sobre os ataques realizados por uma organização que ficou conhecida como uma facção criminosa, chamada PCC (relativa a Primeiro Comando da Capital), em algumas cidades do estado de São Paulo, além de rebeliões ocorridas dentro de alguns presídios. Ao longo do encontro, vários participantes relatam episódios vistos na televisão e/ou ouvidos de colegas. No trecho 02 , porém, NS é a única a dar contribuições, e HM acompanha sua fala. 


\section{Trecho [02] AphasiAcervus NS 18.05.06 morreu né a: como chama a}

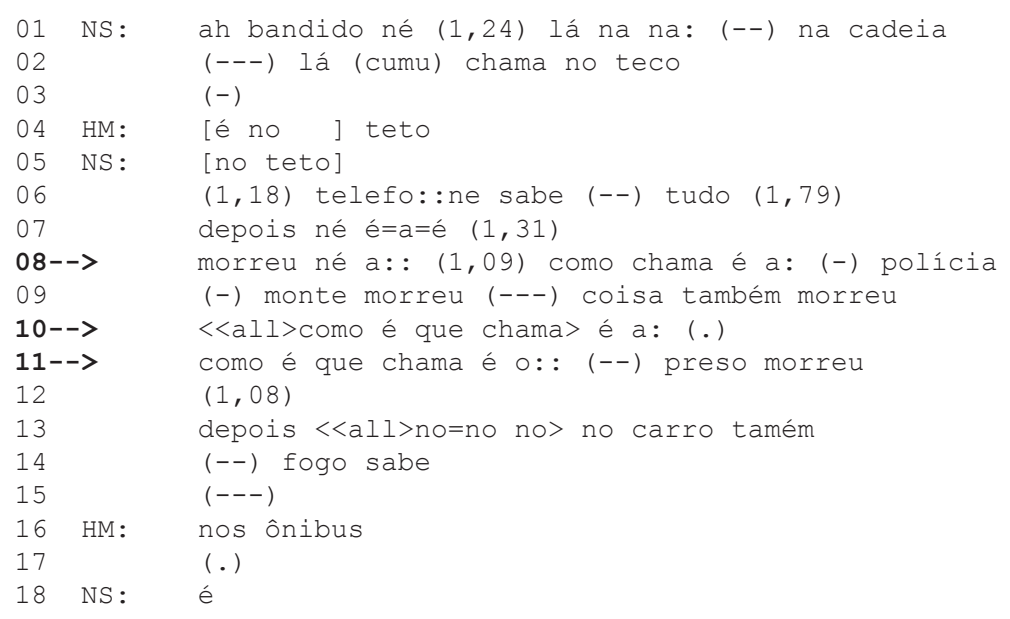

A fala de NS é marcada pela maior ocorrência de substantivos e advérbios, em detrimento de verbos, como se pode observar já nas linhas 01, 02, 13 e 14. No entanto, essa característica de sua produção não interfere no tipo de análise que é empreendida neste artigo. Nas linhas 08 e 10-11 encontram-se as realizações analisadas neste trecho.

Ao revelar que policiais morreram durante a rebelião, NS diz morreu né a como chama é a polícia, que poderia ser esquematizada da seguinte maneira:

\begin{tabular}{|c|}
\hline $\begin{array}{c}\text { morreu né a } \\
\text { a polícia }\end{array}$ \\
\hline
\end{tabular}

Neste caso, NS se vale não só de pausas entre uma e outra produção do determinante, como também utiliza produtivamente marcadores hesitativos como como chama e é, que denotam a busca pelo nome. Essa busca termina com a retração para o início do NP e a produção do nome. Interessa observar, porém, que as características prosódicas do trecho diferem das características observadas no fragmento anterior, ilustrativo da produção da fala não-afásica. 


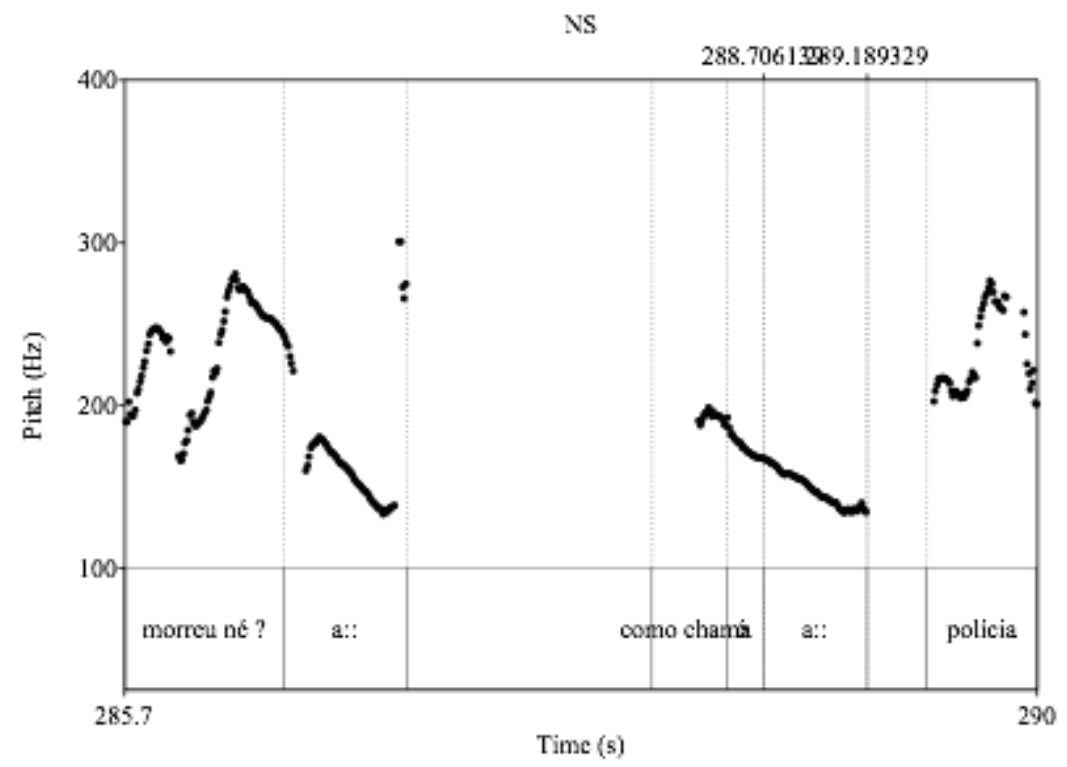

Figura 2. Curva entoacional para "morreu né a como chama é a polícia”.

Na figura 2, nota-se que 1) a duração da matriz não é significativamente maior que a duração da repetição (na verdade, a diferença entre elas é de apenas $8 \%$ e 2) as curvas entoacionais de ambas são significativamente descendentes e atingem o mesmo nível. Ambas têm, portanto, características prosódicas de marcas hesitativas. A retomada da fala de característica não-hesitativa se dará não no início do NP, na retração para o determinante, mas com a produção do nome polícia.

Os dois exemplos apresentados anteriormente ilustram a recorrência de dois padrões distintos de produção das repetições hesitativas, ora na fala não-afásica ora na fala afásica. Na fala não-afásica, há uma relação inversamente proporcional entre a duração da matriz e da repetição em casos de retrações simples em NPs e PPs. Nos casos em que há retração simples de determinantes ou preposições, enquanto a matriz é alongada e produzida com curva entoacional descendente em nível baixo, a repetição é curta e tem curva entoacional em nível mais alto que o nível da matriz, estando boa parte das vezes ligada ao elemento que antecede a matriz. 
No caso das características prosódicas da matriz na fala afásica, não é encontrada a diferenciação entre a matriz e a repetição na maioria dos casos. Na fala afásica, o que se vê é a recorrente semelhança dos valores da duração da matriz e da repetição, assim como do padrão da curva entoacional da matriz e da repetição. Há também os casos em que a curva entoacional se comporta de maneira oposta aos casos de fala não-afásica, ao revelar um padrão ascendente, indicador de continuidade em Português Brasileiro. Esses casos parecem ocorrer concomitantemente à produção de segmentos curtos.

O gráfico abaixo representa a oposição entre a matriz e a repetição, na fala afásica e não-afásica, no que tange ao aspecto da duração, em todo o corpus da tese aqui sumarizada. Observe que os valores da duração da matriz e da repetição são claramente diferenciados na fala não-afásica, enquanto os valores da duração da matriz e da repetição são praticamente os mesmos na fala afásica.

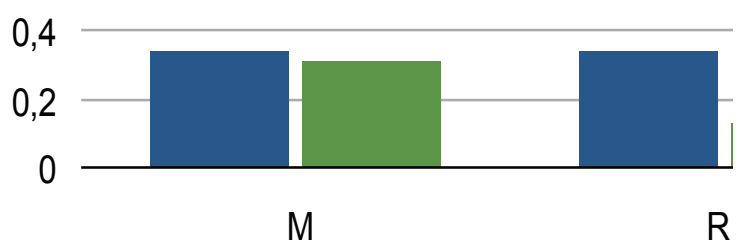

Figura 3. Gráfico da relação entre o valor médio da matriz e o valor médio da repetição na fala afásica e não-afásica em repetições simples.

A manutenção de um padrão alongado da duração na repetição pode ter consequências para a interação. Se se considerar que o alongamento, associado à curva entoacional descendente, caracteriza o processo hesitativo, a manutenção deste padrão na repetição poderia sugerir que o sujeito permanece no processo hesitativo. Essa expectativa somente seria quebrada pela produção do nome, onde ocorre mudança clara no padrão entoacional, indicativo de retomada da fala e do fim do processo hesitativo. Essa característica distingue as duas populações, dado que na fala não-afásica a repetição da matriz vem acompanhada de características prosódicas que a distinguem da produção anterior e apontam o fim do processo hesitativo.

\subsection{Repetições múltiplas em sujeitos afásicos e não afásicos}

Contrariamente ao que foi observado na análise dos casos de repetição simples, no caso das repetições múltiplas o que se observa é sua maior incidência na fala de sujeitos afásicos, quando comparadas às incidências em sujeitos nãoafásicos: as repetições múltiplas correspondem a $70 \%$ dos casos em sujeitos 
VISCARDI - Repetições hesitativas em fala...

afásicos, enquanto elas estão presentes em apenas $29 \%$ dos casos de repetição em sujeitos não-afásicos.

$\mathrm{O}$ formato das repetições múltiplas também varia. Na fala afásica, $62 \%$ dos casos de repetição múltipla referem-se à estrutura M R1 R2 ${ }^{7}$. Na fala não-afásica, esse padrão corresponde a $73 \%$ das ocorrências, o que implica dizer que há um número maior de casos em que as retrações múltiplas são mais extensas na fala afásica.

$\mathrm{O}$ exemplo a ser analisado a seguir corresponde à fala não-afásica e foi extraído de uma conversa em que os participantes do grupo discutem o tema da eleição para prefeito e as diferenças na rede de serviços públicos existentes nos bairros de Campinas.

Os participantes do encontro discutem a estrutura de Campinas em diferentes pontos da cidade e a forma como isso é explorado durante o período eleitoral. EM afirma que, em seu bairro, há uma estrutura mais adequada de serviços, em contraposição às condições existentes em bairros mais afastados do centro da cidade. Na sequência, HM retoma o tópico dos candidatos a prefeito na linha 11, citando a situação de um deles entre as linhas 12-13 e 17-20.

\section{Trecho [03] Aphasiacervus HM 21.10.04 de de de moradia}

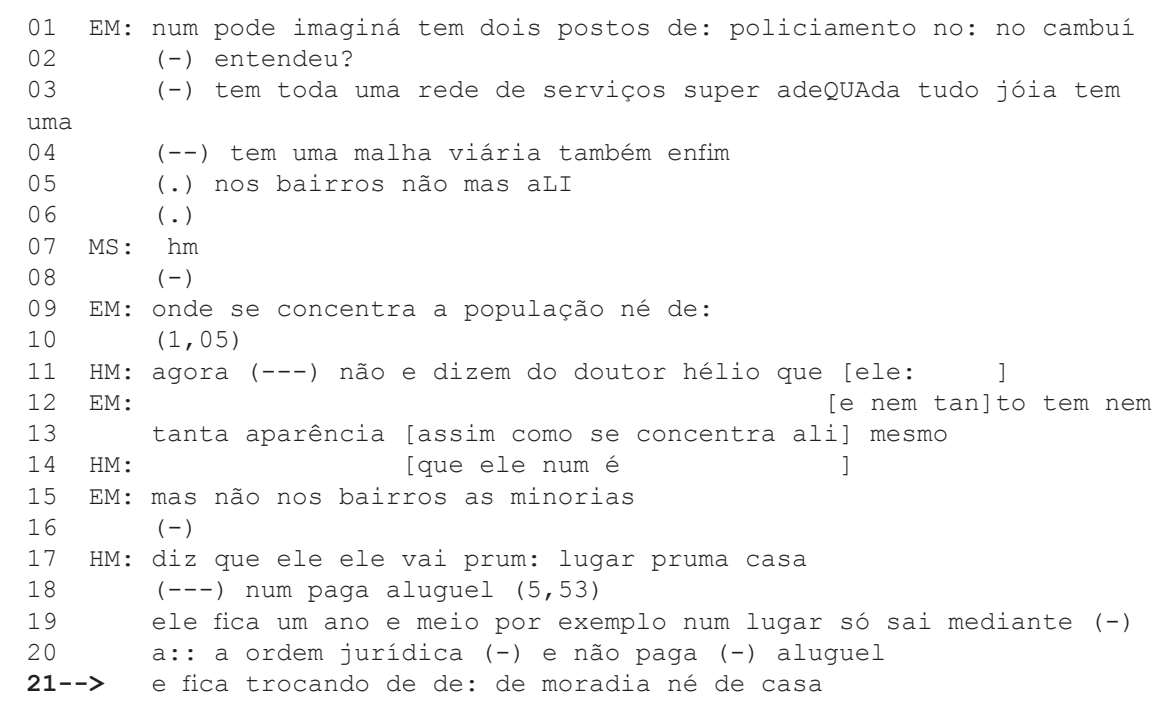

Entre as linhas 17 e 20 a fala de HM apresenta três casos de retração: duas retrações simples (nas linhas 17 e 20) e uma retração múltipla (na linha 21). O trecho prum lugar pruma casa tem caráter de determinação semântica, ao especificar a palavra lugar inicialmente empregada. Já a retração ocorrida na linha repetição.

7. M equivale à matriz e Rx equivale à sequência de repetição, x representando o número da 
20, só sai mediante a a ordem, tem caráter hesitativo, ao ser produzida através da repetição do artigo que inicia a frase preposicional.

No caso da retração múltipla que ocorre na linha 21 , trata-se uma vez mais de uma retração de caráter hesitativo, que se desenvolve até a nomeação, com duas repetições da produção inicial do determinante que compõe a frase nominal.

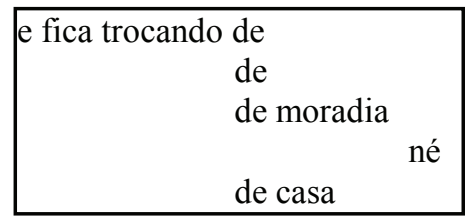

Observe no esboço acima que, além de a retração múltipla motivada pela busca do nome, no mesmo trecho ocorre ainda uma retração simples, fruto do paralelismo relacionado ao enquadramento tópico entre de moradia e de casa.

As características prosódicas da sequência são discutidas a partir da apresentação do gráfico da curva entoacional do fragmento:

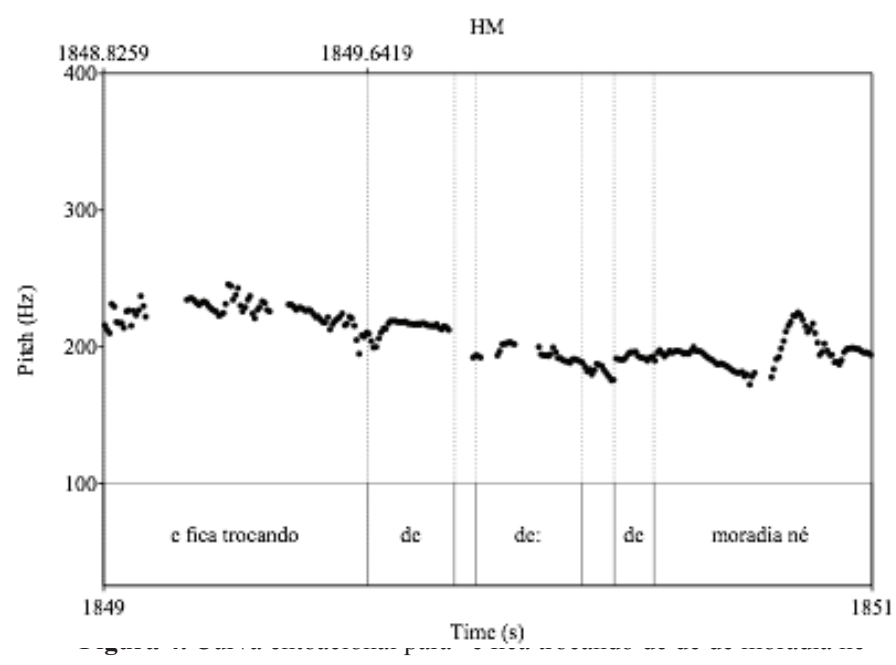

A retração múltipla apresenta mais uma vez uma tendência descendente da curva entoacional, ainda que a curva em cada preposição não seja tão acentuada quanto nos exemplos anteriores.

No caso da matriz, a tendência inicial é de subida para, então, haver uma descida na curva entoacional. Já a primeira repetição tem curva descendente. Ao observar o movimento que se inicia na matriz e termina no final da primeira repetição, será possível perceber a tendência descendente da curva de forma mais clara, o que é quebrado pela ocorrência da segunda repetição, que é produzida em nível. Não há subida de tom na segunda repetição da preposição: ele se mantém próximo ao nível da segunda repetição e será mantido até a produção de né, já 
VISCARDI - Repetições hesitativas em fala...

no final da frase. Neste caso é importante também observar que o intervalo de variação da frequência é menor do que nos exemplos avaliados anteriormente, o que altera a representação gráfica dos movimentos ascendentes e descendentes da curva entoacional.

A partir dos exemplos escolhidos para ilustrarem os padrões de ocorrência das repetições múltiplas em fala afásica e não-afásica, são apresentadas as características gerais das repetições múltiplas em ambos os grupos.

A comparação entre os valores da duração na retração do tipo M R1 R2 revela que os sujeitos não-afásicos distinguem com maior clareza as duas primeiras ocorrências do artigo ou da preposição da última ocorrência da repetição. Observe o quadro:

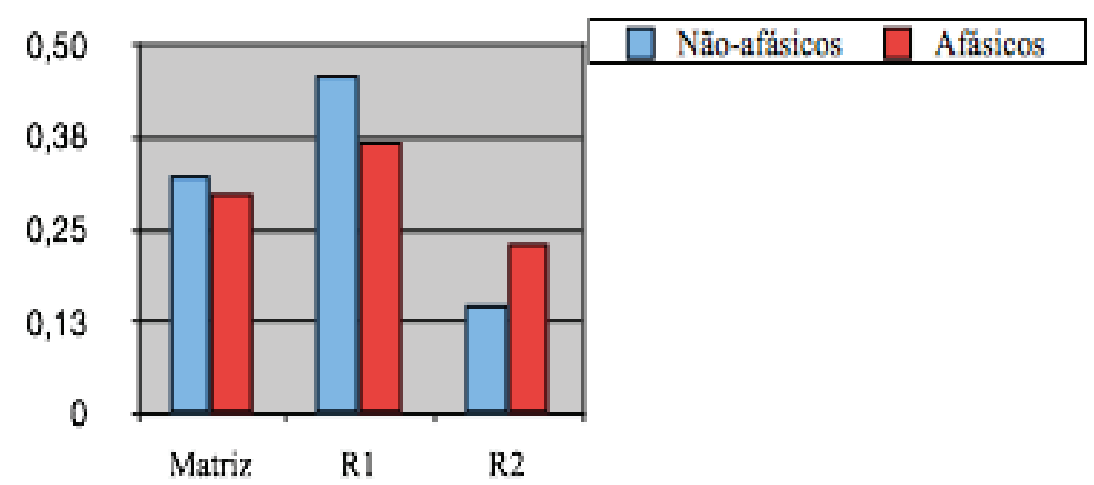

Figura 5. Gráfico da relação entre o valor médio da matriz e o valor médio da primeira e da segunda repetição da fala afásica e não-afásica em repetições múltiplas.

Desta afirmação depreende-se que há uma diferenciação explícita na fala nãoafásica entre as produções que representam uma ocorrência hesitativa da fala, no momento da busca por palavras, e a produção que determina o final dessa busca. $\mathrm{O}$ final da busca é sinalizado através de queda significativa na duração do segmento que antecede a produção do nome, acompanhada também de curva entoacional específica. No caso da curva entoacional, o padrão descendente é utilizado nas ocorrências que têm caráter hesitativo, enquanto a curva produzida em tom mais alto e em nível é empregada na última produção do determinante, quando o nome será produzido. Estes dois elementos, a duração e a curva entoacional, atuam juntos na sinalização da hesitação e, também, de seu fim na sequência de retração múltipla. Poderia-se esperar que a intensidade também tivesse comportamento característico nesse processo de sinalização da hesitação, mas não foi observado um padrão em sua ocorrência.

A comparação entre os segmentos produzidos na retração múltipla de tipo $\mathrm{M}$ R1 R2 R $3^{8}$ revela mais uma vez que os segmentos produzidos na fala afásica são

\footnotetext{
8. Os casos em que há mais de três de repetições da matriz foram reduzidos, por isso não foi feita uma comparação entre suas ocorrências na fala afásica e não-afásica.
} 
mais alongados do que os produzidos na fala não-afásica. Observou-se também que a relação entre as quatro ocorrências do determinante se mostra diferente nos dois contextos.

Assim como no caso das retrações simples, também foi possível estabelecer uma relação entre a proporção dos valores da duração da matriz e da primeira repetição, de um lado, e da segunda repetição, de outro. Enquanto na fala afásica todos os segmentos da sequência têm, na média, duração bastante próxima entre si, na fala não-afásica as três primeiras ocorrências são mais próximas, distanciandose da última ocorrência da repetição. Esse dado confirma mais uma vez o ocorrido na retração múltipla do tipo $\mathrm{M} \mathrm{R} 1 \mathrm{R} 2$, em que há maior diferenciação entre o último elemento repetido e seus pares na fala não-afásica que na fala afásica. Nesses casos, as produções afásicas são bastante mais alongadas que as produções não-afásicas. Além disso, também a diferenciação das três primeiras ocorrências do artigo ou da preposição e de sua última ocorrência revela que os sujeitos nãoafásicos delimitam o espaço de ocorrência da hesitação de forma mais clara do que os sujeitos afásicos.

A curva entoacional acompanha, mais uma vez, a relação entre as primeiras ocorrências de um determinante e sua ocorrência final: enquanto o padrão descendente está associado à matriz e às primeiras ocorrências da repetição, sua última realização se dá com curva em nível, em tom mais alto que o das repetições, sinalizando mais uma vez o final do período hesitativo e a chegada do nome que completa o NP ou o PP.

Esses apontamentos levam à afirmação de que há uma gradiência que determina as características da fala afásica e não-afásica no que tange aos aspectos aqui estudados. De posse dos dados aqui analisados, não é possível afirmar que a prosódia está completamente preservada na fala afásica, mas tampouco é possível afirmar que os sujeitos afásicos não fazem uso dos recursos prosódicos com o intuito de organizar sua produção e garantir maior fluência oral e maior competência comunicativa. Dessa maneira, longe de remeter a uma simplificação relativista, o que este estudo pretende afirmar é que as diferenças na fala afásica e não-afásica não devem ser entendidas e pensadas de forma categórica. Em vez disso, o emprego dos elementos que caracterizam uma determinada atividade verbal devem ser postos em uma escala de gradiência, em que diferentes falantes (afásicos e não-afásicos), de diferentes comunidades, em diferentes situações e condições, fazem uso desses elementos em diferentes proporções, em função também das características que qualificam esses falantes.

\section{CONSIDERAÇÕES FINAIS}

As interações parecem indicar que a repetição e a hesitação são fenômenos inerentes à produção e compreensão da linguagem. Prova disso é que essas ocorrências não são percebidas como anormalidades da fala, tampouco são rejeitadas ou incompreendidas por seus interlocutores. $\mathrm{Na}$ verdade, no que 
VISCARDI - Repetições hesitativas em fala...

tange à fala espontânea, a ocorrência desses fenômenos está atrelada à própria possibilidade de produzir e compreender linguagem.

No caso específico dos sujeitos afásicos analisados aqui, a descrição de seus quadros afásicos sugere "dificuldade no acesso lexical", o que implica uma maior recorrência a recursos como a repetição. Essas características não são, todavia, determinantes e/ou exclusivas da fala afásica, como esse estudo tentou mostrar. Repetições são, por exemplo, observadas nos dois grupos. Na verdade, a afasia não impediu o emprego dos recursos prosódicos também reconhecidos na fala nãoafásica, o que já delineia um dos apontamentos mais importantes deste trabalho: a pergunta não deve ser o que está e o que não está presente na atividade verbal de um sujeito afásico, mas sim como os recursos linguísticos são empregados no decorrer de suas interações. A fala dos três sujeitos afásicos aqui analisados apresentou casos mais ou menos discrepantes ${ }^{9}$ em comparação com os casos não-afásicos, todavia, houve também casos de similaridade com a produção nãoafásica. A relação inversa também é verdadeira: houve casos também discrepantes na produção não-afásica, embora bastante menos frequentes, vale dizer.

Assim, e para exemplificar a partir dos aspectos estudados neste trabalho, em vez de formular hipótese sobre a preservação ou não da prosódia na fala patológica, é preciso pensar como a prosódia é empregada. Da mesma maneira, ao invés de pensar se os afásicos organizam sua fala a partir dos recursos de projeção e retração, é preciso pensar como esses recursos são empregados na atividade verbal desses sujeitos. Dentro da escala de que há ou não prosódia e há ou não projeção e retração, há uma gama de possibilidades de emprego desses recursos linguísticos. São diferentes os fatores que podem influenciar no emprego desses recursos e não será, portanto, exclusivamente a afasia que determinará a ocorrência de uma repetição hesitativa.

As características da fala afásica reveladas neste trabalho indicam, por um lado, que os sujeitos afásicos fazem uso dos mesmos recursos utilizados pelos sujeitos não-afásicos, a saber, dos prolongamentos vocálicos e movimentos de retração e projeção. Todavia, a organização desses recursos revela diferenças na produção dos dois grupos, seja porque os sujeitos afásicos realizam um maior número de retrações múltiplas, seja porque, na fala afásica, o emprego dos recursos prosódicos indicativos da repetição hesitativa é feito em todo o movimento de retração. A indicação prosódica (determinada pelo tom de retomada) de que chega ao fim uma cadeia hesitativa só aparece, na fala afásica, quando o nome é produzido, enquanto na fala não-afásica, essa projeção se dá já na última ocorrência do determinante ou da preposição que compõe o NP ou o PP. Dadas essas afirmações, importa dizer que este estudo não pretende minimizar a importância dessas diferenças entre a fala afásica e não-afásica, mas destacar que, enquanto estratégia, a repetição hesitativa não é indício apenas de problemas na fluência oral, mas também fator de reconstrução de regularidades linguísticas e de fluência (e competência) oral, como observado nos dados aqui analisados.

9. O uso do termo discrepante aqui refere-se a um padrão distinto daquele encontrado para a grande maioria dos casos, seja em fala não-afásica, seja em fala afásica. 
Tais conclusões somente podem ser alcançadas de posse de uma metodologia que permita reflexões sobre os limites e os alcances da atividade verbal e sua organização, seja na fala dita normal, seja na fala dita patológica. Enquanto essa afirmação pode parecer um lugar comum nos estudos da linguagem dita normal, na fala dita patológica é ainda frequente encontrar estudos que se dedicam unicamente a caracterizar a produção e a compreensão dos sujeitos a partir da aplicação de testes metalinguísticos. O problema com esta metodologia não está na aplicação de testes - que pode sim atender a determinados propósitos investigativos - mas naquilo que subjaz a essa metodologia quando usada como único instrumento de avaliação da fala dita patológica, a saber, um pensamento normativo e estruturalista acerca da linguagem.

A metodologia empregada neste trabalho deixa entrever tais fenômenos como estratégias de reconstrução linguística da fluência oral, linguístico-interativa. Essa perspectiva altera, da mesma forma como sugerido em Scarpa (2006), o próprio conceito de fluência, ao reconhecer que a fala fluente, da forma como sugerida nos estudos de Afasiologia e Neurolinguística, é um padrão abstrato, irreal. Os dados de interação mostram o quanto a fala é entrecortada mas, ainda assim, fluente. E é justamente por mostrar a dinâmica do funcionamento dos recursos linguísticointerativos tradicionalmente conhecidos como disfluências que o ambiente do CCA é essencialmente importante para a análise empreendida aqui. Assim como os testes não fornecem tais dados e ações reflexivas dos sujeitos, os protocolos fechados também não o fazem.

Neste estudo, a coordenação e a articulação entre os recursos linguísticos, cognitivos e interacionais de uma atividade verbal se deixam ver na descrição e análise de cada dado. Essa articulação se mantém preservada nos sujeitos afásicos aqui estudados, haja vista que eles estão a todo tempo enfrentando suas dificuldades a partir do emprego de suas habilidades linguísticas, mobilizadas diferentemente em função das necessidades que se articulam no decorrer da atividade verbal em um emaranhado de escolhas coordenadas e orquestradas pelo próprio sujeito afásico, em um ambiente altamente cooperativo (que é o da interação social).

\section{REFERÊNCIAS BIBLIOGRÁFICAS}

ARBUTHNOTT, K. D. (1996). To repeat or not to repeat: Repetition facilitation and inhibition in sequential retrieval. Journal of Experimental Psychology: General, 125, 261-283.

AUER, P. (2009a). On-line syntax: thoughts on the temporality of spoken language. Language Sciences 31, p. 1-13. . (2009b). Projection and Minimalistic Syntax in Interaction. Discourse Processes, 46:2, p. 180205.

; PFÄNDER, S. (2008). Multiple retractions in spoken French and spoken German. A contrastive study in oral performance styles. Cahier de Praxématique 48, p. 57-84.

DELL, G. S.; MARTIN, N.; SCHWARTZ, M. F. (2007). A case-series test of the interactive two-step model of lexical access: Predicting word repetition from picture naming. Journal of Memory and Language, 56, p. 490-520. 
VISCARDI - Repetições hesitativas em fala...

FILLMORE, C W. (1979). On fluency. In: C W. FILLMORE; D. KEMPLER; W. S. Y. WANG (org.). Individual differences in language ability and language behavior. New York: Academic Press, p. $85-101$.

GOODGLASS, H.; KAPLAN, E. (1972). The Assessment of Aphasia and Related Disorders. Philadelphia, PA: Lea \& Febiger.

GUMPERZ, J. (1982). Discourse Strategies. (Studies in Interactional Sociolinguistics 1). Cambridge: University Press.

JUBRAN, C. C. A. S. A perspectiva textual-interativa. In: JUBRAN, C. C. A. S.; KOCH, I. G. V. (org.). Gramática do Português Culto Falado no Brasil — volume 1. Campinas: Ed. Unicamp, 2006.

KOCH, I. V. (1997). O texto e a construção dos sentidos. São Paulo: Contexto.

MARCUSCHI, L. A. (1996). A repetição na língua falada como estratégia de formulação textual. In: KOCH, I. G. V. (Org.). Gramática do português falado, VI: Desenvolvimentos. Campinas, SP: Editora da Unicamp/FAPESP, p. 95-129.

. (1999). A hesitação. In: NEVES, M. H. de M. (Org.). Gramática do português falado., VII: Novos estudos. Campinas, SP: Editora Unicamp.

. (2006). Repetição. In: JUBRAN, Clélia Cândida A. Spinardi; KOCH, Ingedore G. Villaça (Org.). Gramática do português falado no Brasil: construção do texto falado. Campinas, SP: Editora da Unicamp, v.1, p. 219-254.

MICELI, G.; CAPASSO, R.; CARAMAZZA, A. (2004). The relationships between morphological and phonological errors in aphasic speech: Data from a word repetition task. Neuropsychologia, v. 42 , p. $273-287$.

MIRA, C. (2012). Afasia e interação: uma análise da dinâmica de turnos e da gestão do tópico nas práticas conversacionais de sujeitos afásicos e não-afásicos. Tese de doutorado. Instituto de Estudos da Linguagem, Unicamp. Campinas: SP.

MORATO, E. M. et al. (2007). Significação, interação e cognição: a dimensão multimodal de práticas linguístico-interacionais envolvendo afásicos e não-afásicos. Projeto CNPQ, Edital 50/2006. Campinas,.

et al. (2008). Competência e metalinguagem no contexto de práticas interativas de afásicos e não-afásicos. Relatório final do Projeto Fapesp. Campinas, Proc.: 06/52950-9.

MOSES, M. S.; SHEARD, C.; NICKELS, L.A. (2007). Insights into recurrent perseverative errors in aphasia: a case series approach. Aphasiology, v. 21, n.10/11, p. 975-1001.

ROHRER, J.D.; KNIGHT, W.D.; WARREN, J.E.; FOX, N.C.; ROSSOR, M.N.; WARREN, J.D. (2008). Word-finding difficulty: a clinical analysis of the progressive aphasias. Brain, v. 131, n.1, p. $8-38$, janeiro.

SCARPA, E. (1995). Sobre o sujeito fluente. Cadernos de Estudos Linguísticos, v. 29, p. 163-184, jul-dez.. . (2006). (Ainda) sobre o sujeito fluente. In: LIER-DE VITTO, M. F.; ARANTES, L. Aquisição, Patologias e Clínica de Linguagem. São Paulo: Editora PUCSP EDUC, p. 161-180..

SELTING,M.; AUER,P; COUPER-KUHLEN, E. (1998). Gesprächsanalytisches Transkriptionssystem (GAT). Linguistische Berichte, v. 173, p. 91-122.

TAGLiAfERRE, R. (2008). Formas e Funções da Repetição no Contexto das Afasias. Dissertação de Mestrado, Instituto de Estudos da Linguagem, UNICAMP. 
TANNEN, D. (2007). Talking Voices: Repetition, Dialogue and Imagery in Conversational Discourse. 2nd. Edition Edição. New York: Cambridge University Press.

Notação de transcrição

Fenômenos sequenciais

[ ] : sobreposição

$=$ : encadeamento rápido e sem pausa entre turnos

\section{Pausas}

(.) : micropausas

(-), (--), (---) : pausas curtas, médias e longas, de até um segundo

$(1,35)$ : pausas medidas, acima de um segundo

\section{Fenômenos segmentais}

$:$ : :, ::: alongamentos, de acordo com duração

\section{Prosódia}

? grande subida na curva entoacional

, subida na curva entoacional

- plateau

; queda leve na curva entoacional

. queda brusca na curva entoacional

\section{Descrições ao longo das transcrições}

$<<$ tossindo $>>$ atividade simultânea à fala

(sapato) transcrição incerta

$((\ldots))$ trecho de transcrição não apresentado 
